\title{
Effects of oestrogen treatment on testicular descent, inguinal closure and prostatic development in a male marsupial, Macropus eugenii
}

\author{
D. Coveney, G. Shaw and M. B. Renfree \\ Department of Zoology, The University of Melbourne, Victoria 3010, Australia
}

This study reports the effect of oestrogen treatment on the development of the genital ducts, prostate gland, testicular descent and inguinal canal closure in male tammar wallaby young treated with oestrogen over four time spans during the first 25 days of pouch life (days 0-10, 10-15, 15-25 and $0-25$ ) and sampled at day 50 . In control males, the Müllerian ducts had regressed and the Wolffian ducts had developed into the vas deferens and epididymis. The prostate gland had formed epithelial buds extending from the ventral, lateral and posterior walls of the urethra. The testes were in the neck of the scrotum and the gubernaculum and processus vaginalis were present at the base of the scrotum. In most males treated with oestradiol from day 0 to day 25 , the testes had failed to descend by day 50 . The gubernaculae were long and thin. The retained
Müllerian ducts formed a lateral vaginal expansion like that of normal day 50 females. The Wolffian ducts of the males treated on days 0-25 were regressed, but were present in males in the other three treatment groups. The prostate glands were hyperplastic and epithelial budding was highly invasive. Some treated males from the day 10-25 and 0-25 groups had inguinal hernias. These results demonstrate that oestrogen treatment has profound effects on the development of the internal genitalia of a male marsupial, preventing inguinal closure and interfering with testicular descent. Therefore, the tammar wallaby may provide a useful experimental model animal in which to investigate the hormonal control of testicular migration and closure of the inguinal canal.

\section{Introduction}

Testicular hormones are essential for sexual differentiation of male mammals (for a review, see George and Wilson, 1994). In all eutherian mammals studied, androgens stimulate the Wolffian duct to form the epididymis and vas deferens, virilize the urogenital sinus and phallus, and induce testicular descent. The testes also produce the Müllerian inhibitor that induces regression of the Müllerian ducts and may have a role in testicular descent (Hutson, 1985; Behringer et al., 1994; Josso and di Clemente, 1999).

Sexual differentiation in marsupials is similar to that of eutherian mammals but occurs after parturition and extends over a relatively longer time course. Among marsupials, the details of sexual differentiation are best understood in the tammar wallaby (Macropus eugenii). At birth the gonads are histologically undifferentiated, but seminiferous cords form in testes by day 2 after birth, accompanied by onset of Müllerian inhibiting substance (MIS) and androgen production (Hutson et al., 1988; O et al., 1988; Renfree et al., 1992). MIS is secreted through an extended period of pouch life, although the Müllerian ducts have regressed in males by about day 25 (Hutson et al., 1988; Whitworth et al., 1997). The testosterone content of developing testes,

Email: d.coveney@zoology.unimelb.edu.au but not ovaries, increases sharply after birth and remains high until day 45 (Renfree et al., 1992; Wilson et al., 1999). Prostatic buds start to develop under the influence of androgens between day 20 and day 25 after birth (Shaw et al., 1988, 2000; Lucas et al., 1997; Ryhorchuk et al., 1997; Leihy et al., 2001). As in eutherian mammals, testicular descent occurs in two phases. Transabdominal migration, associated with gubernacular enlargement, occurs between day 10 and day 20 after birth when the testes migrate from high in the abdomen to the internal inguinal ring. This is followed by inguino-scrotal descent as the testes pass through the inguinal canal, reaching the bottom of the scrotum by about day 60 after birth (Hutson et al., 1988; Renfree et al., 1996).

There is growing evidence that oestrogens can influence male sexual differentiation. The two forms of oestrogen receptor ( $E R \alpha$ and $E R \beta)$ occur in a number of male reproductive organs and ducts including the prostate gland, vas deferens and seminal vesicles, and in the Sertoli cells, Leydig cells and germ cells of the testis (Eddy et al., 1996; Jefferson et al., 2000; Nielsen et al., 2000; Hess et al., 2001). Double gene knockouts ER $\alpha$ and ER $\beta$ ( $\alpha \beta E R K O)$ cause transdifferentiation of ovaries to testes in female mice, and in males inhibit testis fluid re-absorption and result in sterility (Couse et al., 1999, 2000; Jefferson et al., 2000; Korach, 2000; Pentikainen et al., 2000; Hess et al., 2001). 
D. Coveney et al.

Aromatase is also present in the testis and spermatogenesis is disrupted in male aromatase knockout (ArKO) mice (Robertson et al., 1999; O'Donnell et al., 2001). Oestrogens also affect male urogenital development. In male rodent fetuses treated with diethylstilboestrol (DES) the Müllerian ducts are retained, prostatic development is inhibited, the testes remain intra-abdominal with an abnormal gubernaculum and the phallus is feminized (McLachlan et al., 1975; Gill et al., 1979; Yasuda et al., 1985; Grocock et al., 1988; Prins, 1992; vom Saal et al., 1997; Prins et al., 2001).

The most marked effects of oestrogen treatment in male mammals are observed in marsupials (Renfree et al., 2001), although the effects differ with different doses and treatment schedules. Both the external and internal genitalia of North American opossums (Didelphis virginiana) become completely feminized after treatment with oestradiol dipropionate for 30 days after birth and the Wolffian ducts are extremely dilated (Burns, 1939, 1942, 1955, 1961). Similarly, male short-tailed grey opossums (Monodelphis domestica) treated with oestradiol dipropionate retain the Müllerian ducts, but unlike in Didelphis, have regressed Wolffian ducts (Fadem and Tesoriero, 1986). The development of the prostate gland is inhibited, the testes remain intra-abdominal and the phallus is feminized (Fadem and Tesoriero, 1986).

Tammar pouch young are larger and more developed at birth than opossums (400 mg at birth compared with $100 \mathrm{mg}$ ) and it is possible to treat the neonates with oral doses of exogenous steroids (Shaw et al., 1988; Renfree and Shaw, 2001). Pouch young treated with oestrogen for 25 days after birth and examined at the end of treatment had limited sex reversal of the internal genitalia, including underdevelopment of the processus vaginalis, inhibition of testicular transabdominal migration, persistent Müllerian ducts and reduced Wolffian ducts (Shaw et al., 1988).

When male young were treated with oestradiol benzoate from the day of birth to day 25 after birth but left until day 50 after birth before autopsy (Coveney et al., 2001), they developed one of two distinct phenotypes, depending on the duration of gestation. Complete gonadal sex reversal occurred in young born approximately $24 \mathrm{~h}$ prematurely on day 25 of pregnancy. The testes of these young were morphologically identical to the ovaries of day 50 females and their germ cells had entered meiosis. Young born at full term on day 26 or later (mean duration of gestation is 26.5 days; Renfree et al., 1989) and treated with oestrogen developed dysgenetic testes with abnormal Sertoli cells and atrophy of the seminiferous tubules and tunica albuginea. In the present study, the effects of this oestrogen treatment on testicular descent and the development of the internal genitalia are reported.

\section{Materials and Methods}

\section{Animals}

Tammar wallabies (Macropus eugenii) of Kangaroo Island origin were kept in open grassy yards in our breeding colony in Melbourne, Victoria. Food was supplemented with lucerne cubes, oats and fresh vegetables. Pouch young were removed (RPY) to reactivate the diapausing embryos, so that birth would occur at day $26.5 \pm 0.4$ later (TyndaleBiscoe et al., 1987; Renfree et al., 1989). Animals were checked for birth at least once a day from day 24 after RPY, and the day on which the young were first observed was termed day 0 after birth. The pouch young were examined with an otoscope to determine sex by the presence of scrotal bulges (male) or mammary primordia (females) (O et al., 1988).

All animal handling and experiments conformed to the Australian National Health and Medical Research Council's (1990) guidelines and were approved by institutional animal experimentation ethics committees.

\section{Experimental groups}

Male pouch young were treated with oestradiol benzoate in arachis oil by mouth via a catheter tube beside the teat (1.2-2.5 $\mathrm{mg} \mathrm{kg}^{-1}$ day $^{-1}$; Organon Labs, Morden) as described by Shaw et al. (1988) and Renfree et al. (2001) either from day 0 to day $25(n=11)$ or over three other treatment periods (days $0-10, n=2$; days $10-25, n=4$; days $15-25, n=2$ ) that coincide with important developmental stages (Fig. 1). The number of animals in these last three groups was limited by availability of male neonates. A control group of male young $(n=8)$ was treated with arachis oil alone from day 0 to day 25.

At day 50 after birth the young were killed by an i.p. overdose of sodium pentobarbitone $\left(60 \mathrm{mg} \mathrm{ml}^{-1}\right)$. The morphology of the external genitalia was recorded and the width and length of the scrotum was measured. The animals were dissected for gross examination of the internal genitalia, in particular the presence of the Wolffian and Müllerian ducts, position of the testes and degree of gubernacular development. Patency of the inguinal canal was assessed by pushing a $1 \mathrm{~mm}$ blunt probe into the left internal inguinal ring. Young were fixed in $10 \%(\mathrm{v} / \mathrm{v})$ neutral buffered formalin, embedded in paraffin wax, cut into serial sections ( $8 \mu \mathrm{m}$ thickness), and stained with haematoxylin and eosin. One gonad was removed from the animals treated from day 0 to day 25 for the complementary study (Coveney et al., 2001). The urogenital systems of six of the eight controls, six of the 11 day 0-25 oestrogen-treated young and all eight young treated for the shorter time periods were fixed and examined histologically. This included five of the animals with dysgenetic testes and one with completely sex-reversed testes from the previous study (see Table 1). No differences were observed in this study in urogenital structure of males with dysgenetic testes and the male with sex-reversed testes, so all six animals are reported as a single group. Urogenital tracts from five female pouch young at day 50 after birth and one whole female pouch young at day 50 after birth were fixed in 10\% (v/v) neutral buffered formalin, embedded in paraffin wax and cut into serial sections ( $8 \mu \mathrm{m}$ thickness) for histological comparisons with control and oestradiol-treated day 50 males. 


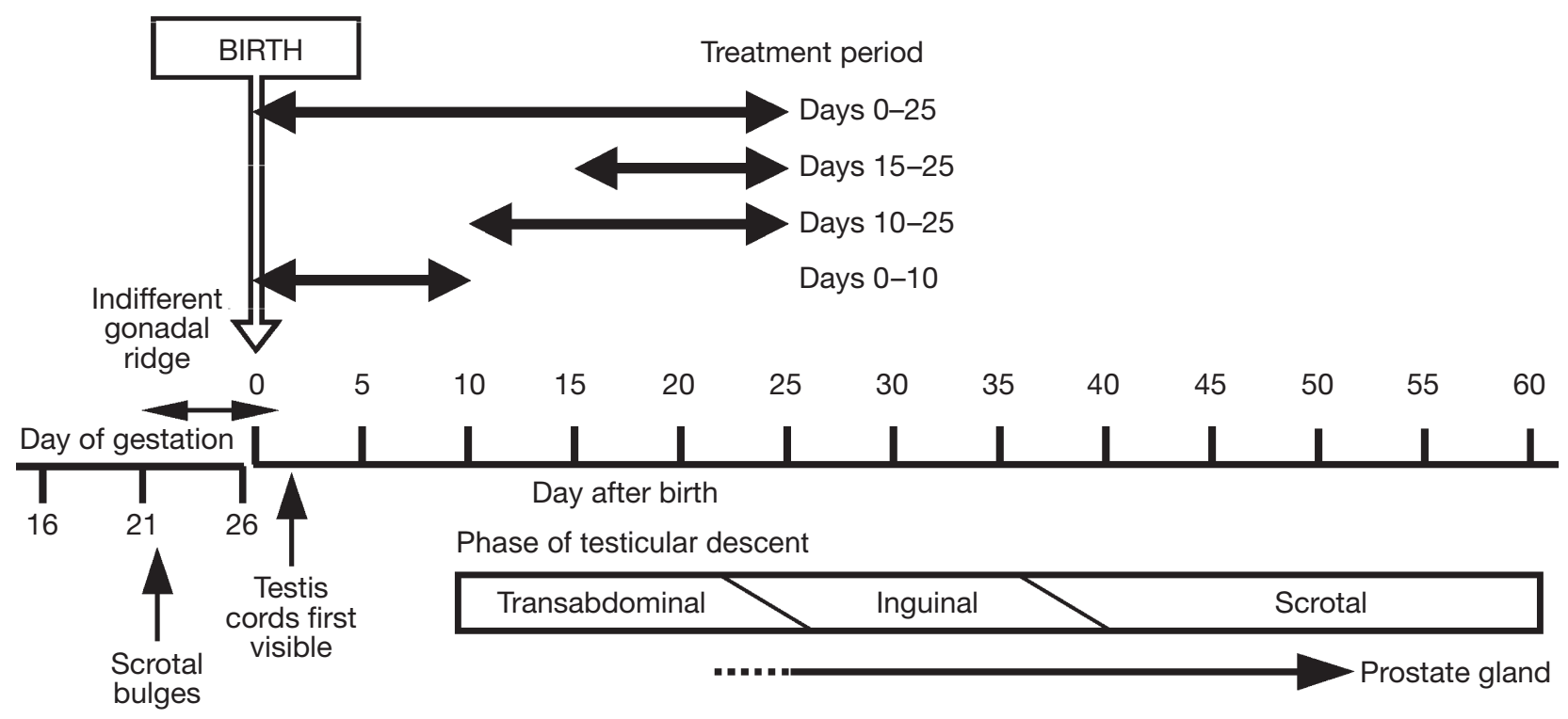

Müllerian duct

Wolffian duct regression in female

Fig. 1. The timing of key events of sexual differentiation in tammar wallabies in relation to the treatment periods. The gonads are histologically undifferentiated at birth (day 26.5 of gestation), but by day 2 after birth the testes have differentiated and are producing androgen and Müllerian inhibiting substance (MIS). A complete Müllerian duct is present in male and female neonates and this regresses in males between about day 6 and day 35 after birth. Neonates have a functional mesonephric kidney and the Wolffian duct is the main urinary duct at the start of pouch life. The Wolffian duct regresses in females between day 10 and day 25 after birth, as the metanephric kidney starts to function and the ureters become the main urinary ducts. Prostatic buds start to form in the urogenital sinus epithelium of males between day 20 and day 25 after birth.

\section{Duct volumes}

Volumes of lumen and surrounding tissue (epithelium and mesenchyme) of the Müllerian ducts of treated males $(n=5)$ and females $(n=5)$ were calculated by a point counting procedure using a coherent square test system $\left(1(p)=10 \mathrm{~mm} ; \mathrm{a}(\mathrm{p})=100 \mathrm{~mm}^{2}\right)$ (Weibel, 1979; Gundersen et al., 1988) on a Zeiss Axiovert $35 \mathrm{M}$ inverted microscope equipped with a Sony high-resolution video system. One Müllerian duct was assessed in each animal and points were taken from every tenth section starting at the anterior end of the ovary and terminating at the future anterior vaginal expansion, where the two ducts first fuse.

\section{Statistical analysis}

Measurements of scrotum dimensions and Müllerian duct volumes for treated and control pouch young were compared using a two-sample $t$ test.

\section{Results}

Gonadal position, gubernaculum and processus vaginalis

The testes of all control males were visible through the skin and were located at the neck of the scrotum (Fig. 2a,
Table 1). A well-developed vas deferens ran from the testis up the inguinal canal and across to the top of the urogenital sinus at the base of the bladder (Fig. 3a), and the gubernaculum extended from the distal portion of the testis and epididymis, at the neck of the scrotum, to the base of the scrotum (Fig. 3b). The processus vaginalis extended to the centre of the scrotum and separated the gubernaculum into its three distinct parts: the plicae gubernaculi, pars vaginalis gubernaculi and pars infravaginalis gubernaculi (as described by Backhouse and Butler, 1960) (Fig. 3). The processus vaginalis was lined with squamous epithelial cells similar to those of the peritoneum. The pars gubernaculum consisted primarily of mesenchymal cells, but the cremaster muscle was developing on its periphery (Fig. 3a,b). A $1 \mathrm{~mm}$ blunt probe could be passed through the internal inguinal ring, but was stopped by a constriction in the inguinal canal above the pubic bone.

Of the nine males treated from day 0 to day 25 that had dysgenetic testes, three had bilateral inguinal hernias, with the testes in the greatly expanded processus vaginalis at the neck of the scrotum, surrounded by loops of the gut (Fig. 2b, Table 1). The other six males had enlarged inguinal canals but no hernias and the testes were located high in the abdomen (Fig. 2d). One of the two males treated from day 0 to day 25 that had sex-reversed testes had a unilateral 
Table 1. Effect of oestrogen treatment of male tammar pouch young between birth and day 25 on testicular morphology and descent, inguinal herniation and urogenital duct development at day 50 after birth

\begin{tabular}{|c|c|c|c|c|c|c|c|c|}
\hline \multirow[b]{2}{*}{ Treatment } & \multirow[b]{2}{*}{ Testis } & \multirow[b]{2}{*}{$n$} & \multicolumn{3}{|c|}{ Testis position } & \multirow[b]{2}{*}{ Hernia } & \multirow[b]{2}{*}{ Wolffian duct } & \multirow[b]{2}{*}{ Müllerian duct } \\
\hline & & & Abdominal & $\begin{array}{l}\text { High } \\
\text { inguinal }\end{array}$ & $\begin{array}{l}\text { Neck of } \\
\text { scrotum }\end{array}$ & & & \\
\hline Control & Normal & 8 & & & 8 & 0 & Developed & Regressed \\
\hline \multirow{2}{*}{ Day 0-10 } & Normal & 1 & & 1 & & 0 & Developed & Small remnants \\
\hline & Dysgenetic & 1 & 1 & & & 0 & Developed & Enlarged \\
\hline \multirow[t]{2}{*}{ Day $10-25$} & Normal & 4 & 1 & & & 0 & Developed & Enlarged \\
\hline & Normal & & & 3 & & 2 & Developed & Small remnants \\
\hline Day $15-25$ & Normal & 2 & & 2 & & 0 & Developed & Small remnants \\
\hline \multirow[t]{3}{*}{ Day 0-25 } & Dysgenetic ${ }^{\dagger}$ & 9 & 6 & & & & Regressed* & Enlarged \\
\hline & & & & & 3 & 3 & Regressed** & Enlarged \\
\hline & Sex-reversed ${ }^{+}$ & 2 & 1 & & 1 & 1 & Regressed** & Enlarged \\
\hline
\end{tabular}

*Based on four young from which sections were made.

**Based on one young from which sections were made.

${ }^{+}$Data from Coveney et al. (2001).

inguinal hernia on the right hand side, with an inguinal testis, whereas the left testis was abdominal.

The testes of all four day 10-25, both day 15-25 and one of two day 0-10 treated males appeared normal with numerous seminiferous cords. Of these animals, one day 10-25 male had abdominal testes and the other animals had testes that were situated high in the inguinal canal (Table 1). Two of the three day 10-25 males that had inguinal testes had unilateral inguinal hernias on their right hand sides (Fig. 3c,d). The other day 0-10 male had dysgenetic testes that were situated high in the abdomen.

The gubernaculae of all treated animals consisted of a dense, dark-staining mass of mesenchymal cells that was easily identifiable in the surrounding light-staining mesenchyme (Fig. 3d). Treated males with abdominal testes had long, thin gubernaculae attached to the testes and Müllerian ducts, which extended through the inguinal canal and terminated in the neck of the scrotum. The gubernaculae of treated males with inguinal testes were thin and extended from the gonad to the neck of the scrotum (Fig. $3 \mathrm{~d}$ ). The processus vaginalis of all treatment groups, whether they had a hernia or not, was larger in crosssectional area (Fig. 3c) and a $1 \mathrm{~mm}$ blunt probe could easily be inserted through the inguinal canal. However, the processus vaginalis, unlike that of controls, extended from the abdominal cavity to the neck of the scrotum only (Fig. 3d). The pars gubernaculum consisted of mesenchymal cells and the cremaster muscle was developing on the periphery. The scrotum of the treated males was significantly smaller than that of control males (width: $5.05 \pm 0.05$ versus $4.27 \pm 0.15 \mathrm{~mm}, P \leqslant 0.05$; length: $6.15 \pm 0.15$ versus $3.86 \pm 0.15 \mathrm{~mm}, P \leqslant 0.05)$.

\section{Duct morphology}

Overall, oestrogen treatment had a feminizing influence on the urogenital ducts, causing retention of the Müllerian ducts and regression of the Wolffian ducts. In control males, the Müllerian ducts were completely regressed with no obvious remnants at either the urogenital sinus or near the testis. The Wolffian ducts were well developed and had differentiated into their adult derivatives, the vas deferens and epididymis. The vas deferens was well defined, with a cuboidal epithelium surrounded by mesenchymal tissue and the lumen was patent from the epididymis to the urogenital sinus. The epididymis was well developed and lined with a layer of cuboidal epithelial cells.

Müllerian ducts were present in all day 0-25 oestradioltreated males (Figs $2 \mathrm{~d}$ and $4 \mathrm{~d}$, Table 1). Although the ducts were enlarged at the urogenital sinus, there was no significant difference in total volume of the tissue (epithelium and mesenchyme) or lumen compared with day 50 females (treated male versus female: lumen: $0.12 \pm 0.02$ versus $0.12 \pm 0.02 \mathrm{~mm}^{3}$; tissue: $0.59 \pm 0.05$ versus $\left.0.64 \pm 0.09 \mathrm{~mm}^{3}\right)$. The Müllerian ducts were small near the testis, but expanded in size towards the caudal end where they entered the urogenital sinus and, as in females, they curved and enlarged to form the anterior vaginal expansion (Figs $2 \mathrm{~d}$ and $4 \mathrm{~d}$ ). In five of the six day $0-25$ oestrogentreated males the Müllerian ducts were patent along the whole length, but in the other oestradiol-treated male the Müllerian ducts terminated in the mesenchyme of the urogenital sinus without entering the lumen. A layer of columnar and cuboidal epithelial cells, identified by their spherical dark staining nuclei similar to that of day 50 females, surrounded the lumina of the ducts. The Wolffian ducts of the day 0-25 treated males had various degrees of regression. Three of the young only had rudiments of the Wolffian duct in the mesenchyme parallel to the Müllerian ducts on both sides, whereas one animal had Wolffian duct rudiments on one side but completely regressed Wolffian ducts on the other side. In the other two young sectioned, including the animal with sex-reversed gonads, no remnants of the Wolffian duct were visible. 

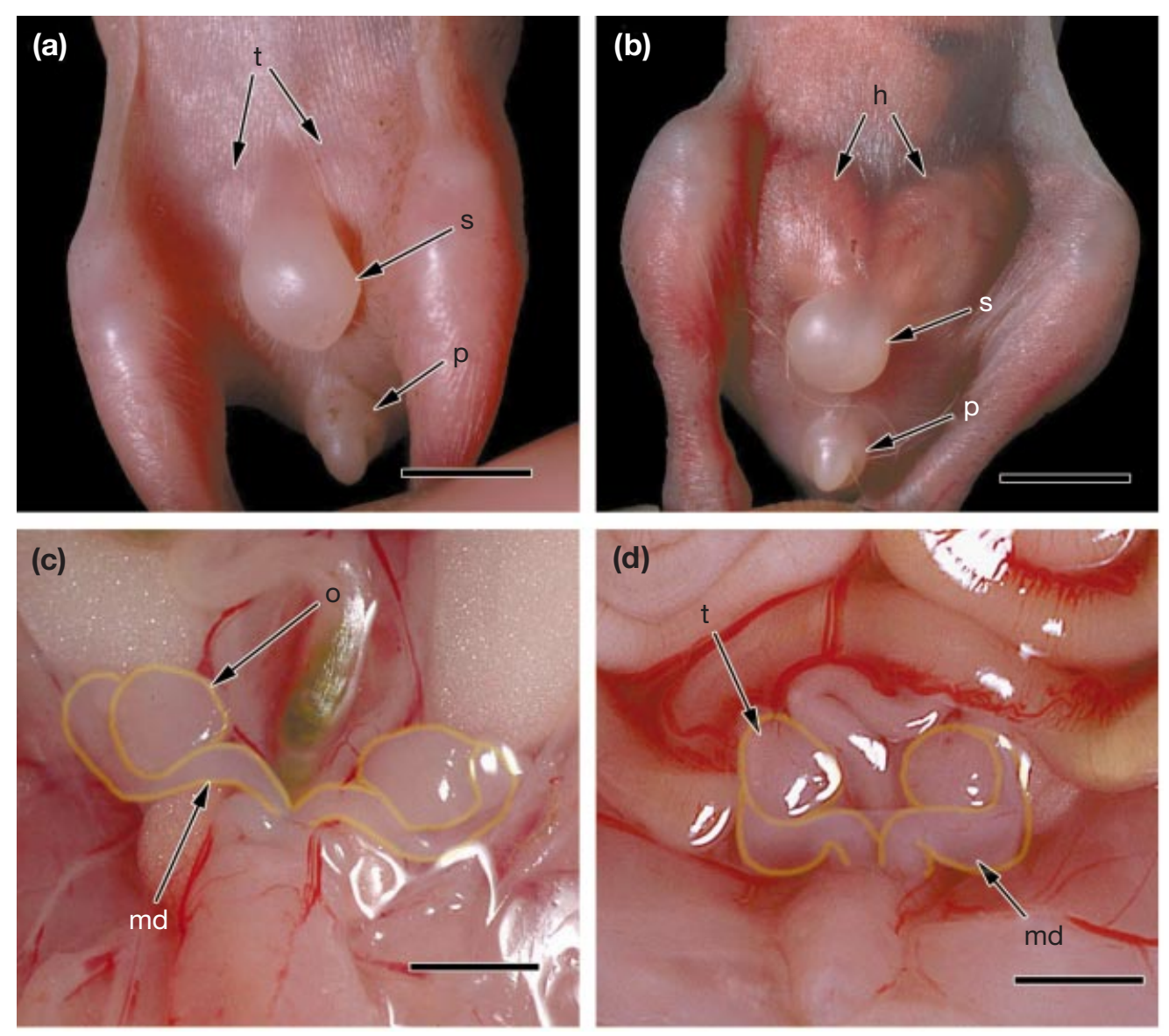

Fig. 2. External and internal genitalia of day 50 tammar wallaby pouch young. (a) The external genitalia of a day 50 control male pouch young. The testes $(\mathrm{t})$ are just visible through the skin at the neck of the scrotum (s), which is cranial to the phallus (p), as in all marsupials. (b) The external genitalia of a day 0-25 oestradiol-treated male with bilateral inguinal hernias (h). (c) The internal genitalia of a day 50 female with abdominal ovaries (o) and Müllerian ducts (md). (d) The internal genitalia of a day 0-25 oestradiol-treated male young, with abdominal testes and retained Müllerian ducts. In (c) and (d) the outline of the Müllerian ducts and gonads has been highlighted in translucent yellow. Scale bars represent $(\mathrm{a}, \mathrm{b}) 10 \mathrm{~mm}$ and $(\mathrm{c}, \mathrm{d}) 5 \mathrm{~mm}$.

In the other oestrogen treatment groups, full-length Müllerian ducts were retained only if the animal was cryptorchid ( $n=2$; see Table 1). The Müllerian duct had regressed along most of its length in all males with descended testes, but remnants persisted in the urogenital sinus. The Wolffian duct was present in all animals and patent along its entire length (Fig. 4b). However, the remnants of the Müllerian ducts fused with the Wolffian duct in the mesenchyme surrounding the urogenital sinus.

\section{Prostate gland morphology}

Oestrogen treatment caused abnormal hyperplasia of the urogenital sinus epithelium, with reduction in prostate gland-like buds. The prostate glands of control males were well developed as described by Lucas et al. (1997), with extensive budding of the epithelium into the surrounding mesenchyme (Figs 4a and 5a,b). The epithelial buds had stratified squamous epithelium, with eosinophilic cytoplasm and dark staining elliptical nuclei (Fig. 5a,d) extended cranially from the ventral, dorsal and lateral walls of the lumen. Towards the posterior end of the urogenital sinus there were no buds and the lumen was surrounded by a layer of stratified squamous epithelium (Figs 4a and 5c).

The urogenital sinus epithelium of the day $0-25$ treated males was hyperplastic and hypertrophic (Fig. 5d-f). The epithelium formed deep folds into the surrounding mesenchyme, forming epithelial ridges along the length of the prostate gland (Figs $4 d$ and $5 d-f$ ). These epithelial folds projected from the ventral, dorsal and lateral walls of the lumen. Unlike control animals, there were no prostatic buds present at any level in the urogenital sinus mesenchyme. The stratified squamous epithelial cells of the urogenital sinus had highly eosinophilic cytoplasm and dark staining elliptic or irregularly shaped nuclei (Fig. 5d-f). 

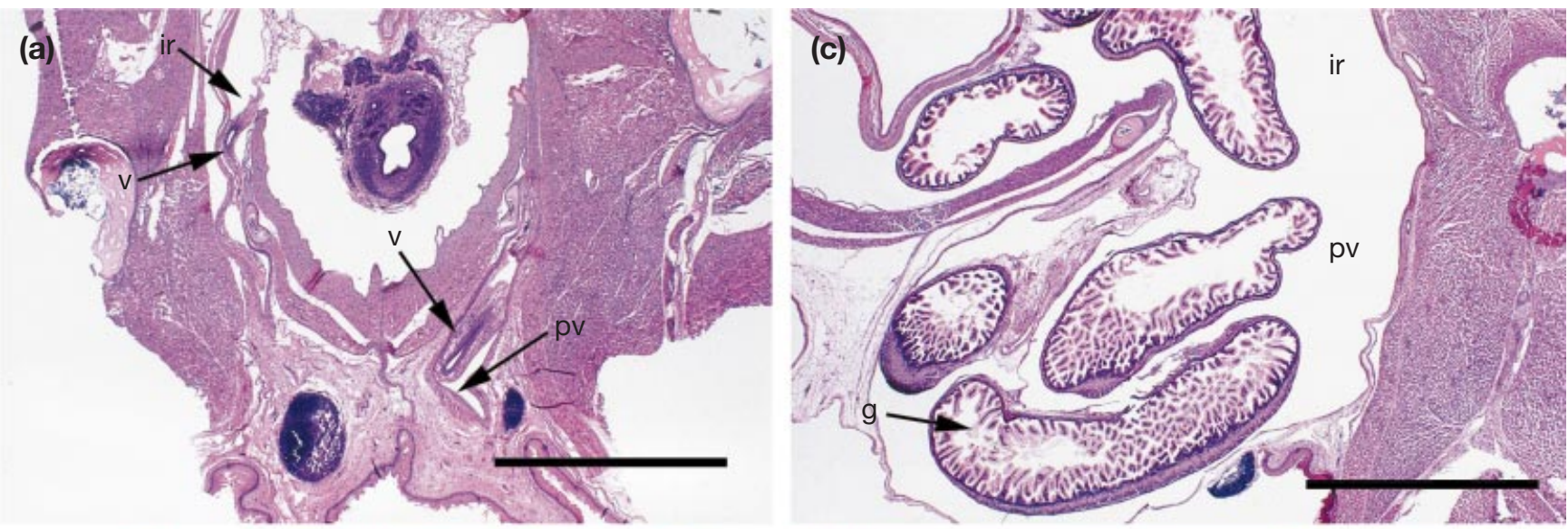

(b)
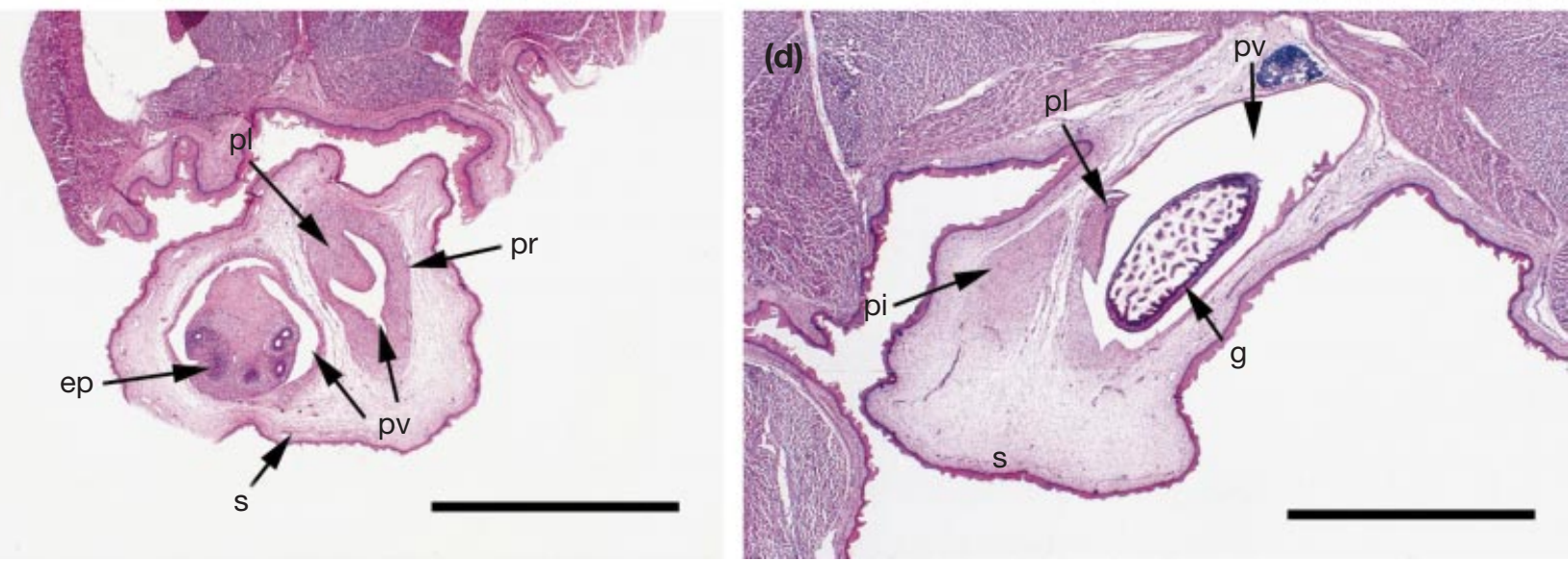

Fig. 3. Sections from two tammar wallabies showing the scrotum, gubernaculum and inguinal canal at two levels from (a,b) a control and $(c, d)$ an oestradiol-treated male. (a) The internal inguinal ring (ir) of a control male with the vas deferens (v) within the processus vaginalis (pv). (b) A more caudal section showing a control male with the processus vaginalis deep in the scrotum (s). The epididymis (ep) and plica gubernaculi $(\mathrm{pl})$ are present within the process, surrounded by the pars vaginalis gubernaculi (pr). (c) The internal inguinal ring of a day 10-25 oestrogen-treated male, with a unilateral inguinal hernia. The internal inguinal ring is enlarged with the gut (g) protruding through. (d) A more caudal section showing the neck of the scrotum of a day 10-25 oestrogen-treated male with the gut at the base of the processus vaginalis. The end of the gubernaculum, the pars infravaginalis gubernaculum (pi), is present at the neck of the scrotum. Scale bars represent $500 \mu \mathrm{m}$.

Prostatic buds had developed in the anterior end of the urogenital sinus of the day 10-25 treated males, similar to that of controls (Figs $4 \mathrm{~b}$ and $5 \mathrm{~g}$ ). In the posterior portion of the urogenital sinus the epithelium was hyperplasic and was folded into the surrounding mesenchyme from the ventral, posterior and lateral walls of the lumen forming longitudinal ridges (Figs $4 \mathrm{~b}$ and $5 \mathrm{~h}, \mathrm{i}$ ). The urogenital sinuses of both the day $0-10$ and day $15-25$ treated young appeared normal with prostatic buds similar to those of controls clearly visible in the anterior of the prostate gland.

\section{Discussion}

Oestrogen administration severely affects development of the urogenital system of neonatal male tammars. Oestrogen-treated males had regressed Wolffian ducts, retained Müllerian ducts, hyperplasia of the urogenital sinus epithelium and prostatic buds. Testicular descent was inhibited and $32 \%$ of the young had inguinal hernias. As oestrogen treatment disrupts testicular differentiation (Coveney et al., 2001), these effects may result from a combination of direct action of oestrogen and reduced production of gonadal hormones.

In eutherians and marsupials, retention and differentiation of the Wolffian duct depends on testicular androgens. Regression of the Wolffian ducts in day 0-25 treated tammar wallaby males indicates that androgen production by the gonads was inhibited by the oestrogen treatment. However, Wolffian ducts were present in the day 0-10, day 10-25 and day 15-25 treated males, indicating that the gonads of animals given shorter treatment produced androgens. This finding is consistent with the relatively normal development of the gonads in most of these animals and indicates that androgen is essential for at least 10 days for 
(a)
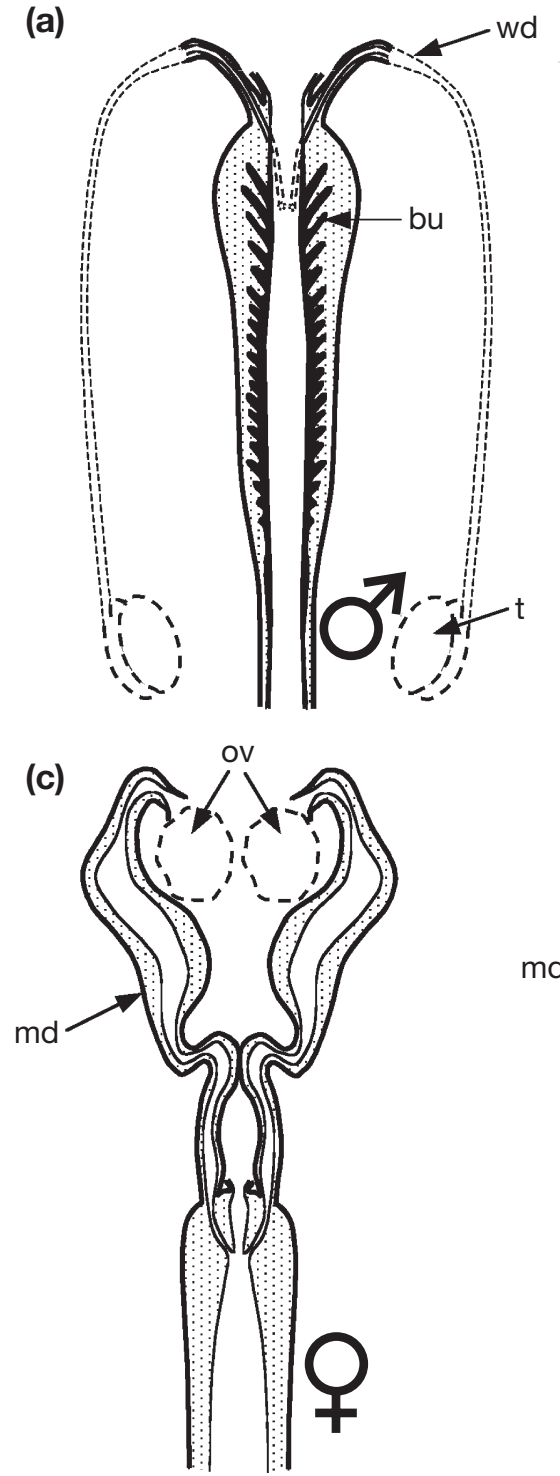

(b)
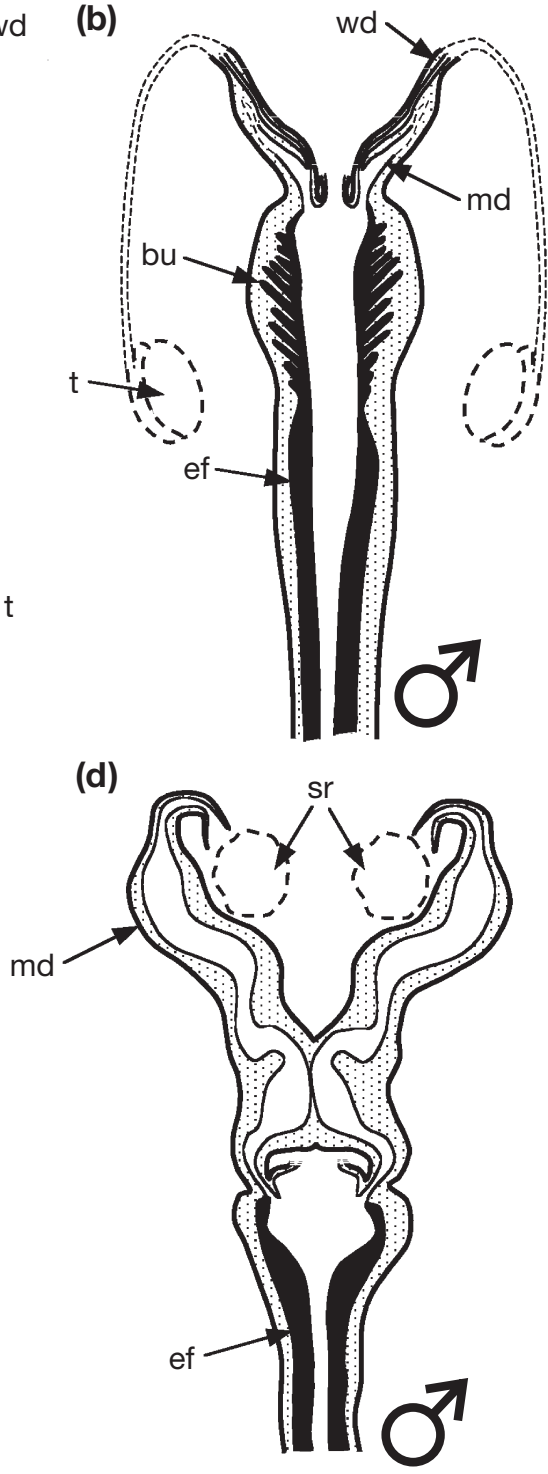

Fig. 4. A two-dimensional reconstruction of the urogenital tracts of control and oestrogen-treated pouch young. (a) The control males had descended testes ( $\mathrm{t}$ ) and well developed Wolffian ducts (wd). Epithelial buds (bu) projected into the mesenchyme of the urogenital sinus along its length. (b) A day 10-25 oestrogentreated male with testes situated high in the inguinal canal, well-developed Wolffian ducts and retained Müllerian ducts (md) near the urogenital sinus. Epithelial buds were present at the cranial end of the urogenital sinus, but in the caudal part, epithelial folds (ef) projected into the mesenchyme. (c) A control female with ovaries (ov) high in the abdomen and well-developed Müllerian ducts that opened into the urogenital sinus. The urogenital sinus epithelium was relatively thin and lacked buds or folds. (d) A day 0-25 oestrogen-treated male with abdominal sex-reversed testes (sr) lacked a Wolffian duct but had retained Müllerian ducts similar to those of control females. The urogenital sinus lacked prostatic buds but hypertrophic epithelial folds were present along its entire length.

retention of the Wolffian duct. This contention is confirmed by the presence of Wolffian ducts in male tammar wallabies that had been castrated at day 10 after birth (Tyndale-Biscoe and Hinds, 1989). In neonatal male short tailed grey opossums, the Wolffian ducts also regressed after oestrogen treatment (Fadem and Tesoriero, 1986). In contrast, the Wolffian ducts of North American opossums treated by painting the litter with $20-25 \mu$ g oestradiol dipropionate 

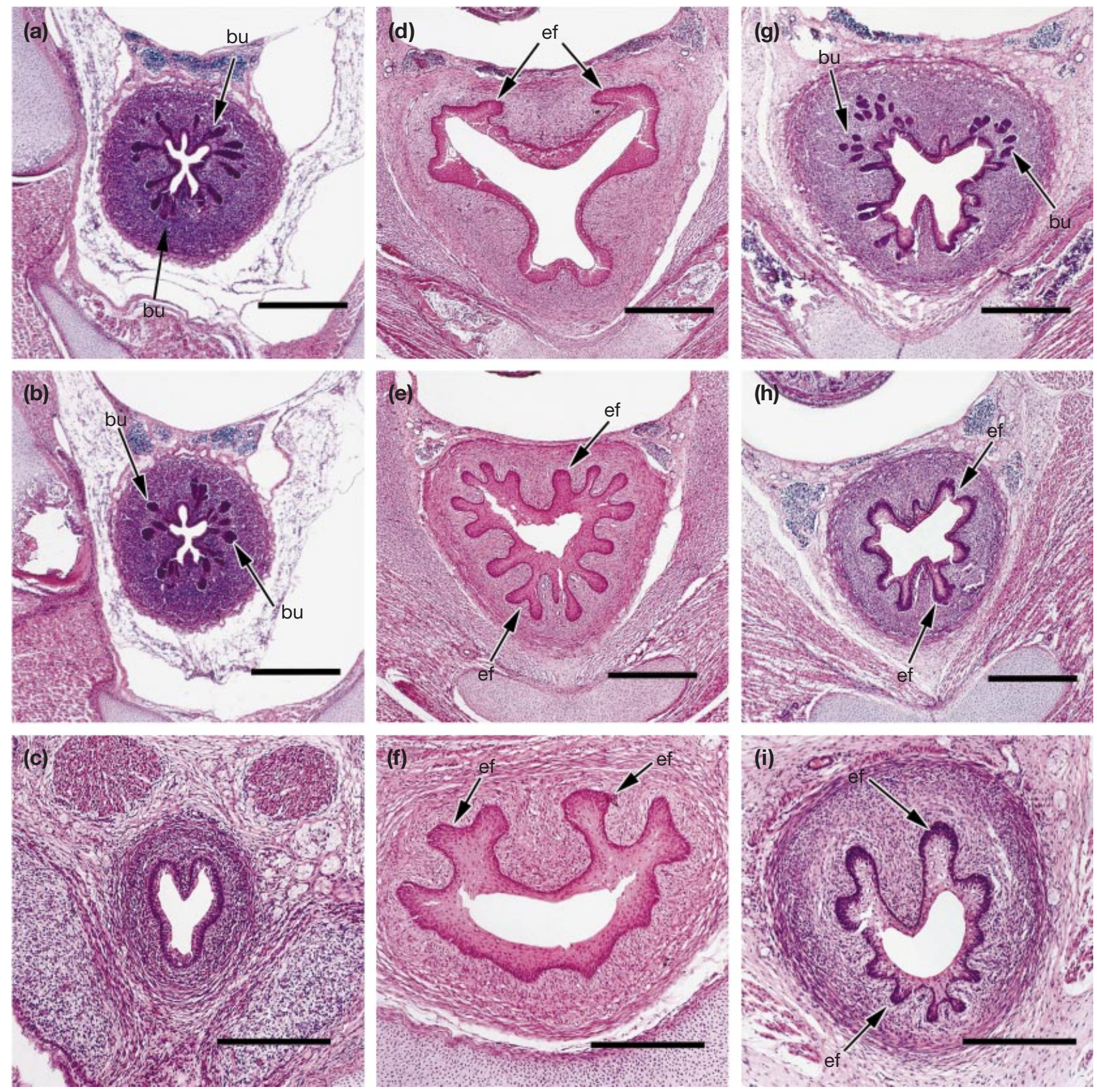

Fig. 5. Sections through the anterior, central and caudal regions of the urogenital sinus of (a-c) a control male, (d-f) a day $0-25$ oestrogentreated male and (g-i) a day 10-25 oestrogen-treated tammar wallaby male. (a) In the control male, extensive epithelial budding (bu) is seen in the anterior (a) and central (b) sections but not in the caudal region (c). (d) A section through the anterior of the urogenital sinus of a day 0-25 oestrogen-treated male shows hyperplasia of both the mesenchyme and epithelium with some epithelial folds (ef) but no prostaticlike buds. (e) A section in the middle of a day 0-25 oestrogen-treated urogenital sinus with extensive hyperplasia of the epithelium, which has formed epithelial folds projecting into the mesenchyme. (f) Posterior section of a day 0-25 oestrogen-treated male prostate gland with hyperplasic epithelial folds. (g) An anterior section of day 10-25 oestrogen-treated male prostate gland with normal prostate gland bud development in which prostate gland-like buds are present in the mesenchyme. In the central section (h) and caudal section (i), the urogenital sinus epithelium is hyperplastic and has formed epithelial folds. Scale bars represent (a,b,d,e,g,h) $500 \mu \mathrm{m}$ and (c,f,i) $250 \mu \mathrm{m}$.

day $^{-1}$ from day 4 to day 18 after parturition were extremely dilated (Burns, 1939, 1942, 1961).

The persistence of the Müllerian ducts in treated males is also seen in oestrogen-treated mice and may reflect inhibition of MIS synthesis or action, or a direct stimulatory effect of oestradiol on the duct mesenchyme (Hutson et al., 
1982; MacLaughlin et al., 1983; Newbold et al., 1984, 1987; Hutson et al., 1985; Grocock et al., 1988; Visser et al., 1998). In adult females, the anterior and lateral vaginae are highly sensitive to oestradiol and have oestrogen receptors (Renfree and Blanden, 2000). Fetal and neonatal mice have oestrogen receptor $\alpha$-immunopositive cells that surround both the Müllerian and Wolffian ducts, indicating that oestrogen may play a role in the regulation and functional differentiation of the epithelium of the genital ducts (Nielsen et al., 2000).

The hyperplasia of the urogenital sinus epithelium in oestrogen-treated male neonates is also presumed to be a direct effect of oestrogen, as longer treatments induced more significant change. In both grey and Virginian opossums, oestrogen treatment of male young completely inhibited prostatic development (Burns, 1939, 1942, 1961; Fadem and Tesoriero, 1986). The differences in response in the genital ducts and urogenital sinus in the three marsupial species may reflect different doses or timing of treatment in the three studies. In developing eutherian males, oestrogen treatment may either stimulate or inhibit prostate gland development depending on timing and dose (Rajfer and Coffey, 1978; Naslund and Coffey, 1986; Nonneman et al., 1992; Prins, 1992; vom Saal et al., 1997; Singh and Handelsman, 1999; Prins et al., 2001). It must be assumed that timing and dose affect marsupials in a similar way.

One of the most striking effects of oestrogen treatment was the induction of cryptorchidism and inguinal hernia. As in eutherians, testicular descent in the tammar wallaby occurs in two phases (Hutson et al., 1988; Griffiths et al., 1994; Renfree et al., 1996). The initial transabdominal migration of testes from a location just caudal to the kidneys to the internal inguinal ring depends on prior outgrowth of the gubernaculum. In eutherian mammals, gubernacular development is highly dependent on testicular MIS production and action, but is androgen-independent (Hutson, 1985; Shono et al., 1994). Gonadal MIS production or action in oestradiol-treated tammar pouch young appears to be compromised, as abdominal testes were always associated with complete Müllerian duct retention, as observed in our earlier study (Shaw et al., 1988). Thus, the failure of gubernacular outgrowth and transabdominal migration in the present study was not unexpected. It could also be a result of inhibition of testicular production of insulin-like factor 3 (INSL3). Outgrowth of the gubernaculum fails in Ins/3 knockout mice (Nef and Parada, 1999; Zimmermann et al., 1999) and oestrogen administration decreases Ins/3 expression in the testis (Emmen et al., 2000; Nef et al., 2000).

Transabdominal migration occurred in one of two day 0-10, three of four day 10-25 and in both day 15-25 treated animals. The day 10-25 and day 15-25 oestrogen treatment periods are well after the initiation of testicular MIS production (Hutson et al., 1988) and androgen production (Renfree et al., 1992), and in all but the cryptorchid cases the testes appeared normal, so there may have been sufficient time for MIS or androgen or both to affect the gubernaculum and induce transabdominal migration. The failure of gubernacular outgrowth and testicular descent prevents mechanical stretching of the scrotum by the descended testis. This probably accounts for the observed smaller scrotum in treated males.

Inguinal hernias were observed after treatment from day 0 to day 25 as well as after treatment from day 10 to day 25 . Failure of inguinal closure and the resulting inguinal hernia occurs in humans with androgen insensitivity syndrome (AIS), in which there is a mutation in the androgen receptor (Atwell, 1962; Hutson, 1986; Barthold et al., 2000). Likewise, male tammar pouch young treated with the androgen receptor inhibitor flutamide develop inguinal hernias (Lucas et al., 1997). Therefore, the inguinal hernias in oestradioltreated male tammars may be a result of androgen deficiency. It is also possible that the continuing presence of the gubernaculum in the inguinal canal may prevent closure, as seen in humans that have abnormal MIS production or action and so develop persistent Müllerian duct syndrome (Hutson et al., 1994; Loeff et al., 1994; Belville et al., 1999).

The results of the present study demonstrate that postnatal treatment with oestradiol has profound effects on the genital ducts and the inguinal canal, preventing inguinal closure and testicular descent. These effects appear to be the result of both alterations of normal testicular MIS and androgen production, and from direct effects of oestrogen on the developing target tissues. These studies have characterized an experimental animal model for the study of inguinal closure, a clinically important process in humans, the endocrine control of which is still poorly understood.

The authors would like to thank Patrick Jackson, Deidre Mattiske, Chris Nave and Andrew Pask for their help with animal handling. The authors would also like to thank Bruce Abaloz and David Paul for their technical support with histology and photography, and Gary Jolley-Rogers for his assistance with microscopy. Animals were collected under permits from South Australian National Parks and Wildlife, and held under permit number RP-95-088 of the Department of Natural Resources and Environment, Victoria. This study was funded by grants from the National Health and Medical Research Council of Australia.

\section{References}

Adham IM, Steding G, Thamm T, Bòllesbach EE, Schwabe C, Paprotta I and Engel W (2002) The overexpression of the Insl3 in female mice causes descent of the ovaries Molecular Endocrinology 16 244-252

Atwell JD (1962) Inguinal hernia in female infants and children British Journal of Surgery 50 294-297

Backhouse KM and Butler H (1960) The gubernaculum testis of the pig (Sus scropha). Journal of Anatomy 94 107-121

Barthold JS, Kumasi-Rivers K, Upadhyay J, Shekarriz B and ImperatoMcginley J (2000) Testicular position in the androgen insensitivity syndrome: implications for the role of androgens in testicular descent Journal of Urology 164 497-501

Behringer RR, Finegold MJ and Cate RL (1994) Müllerian-inhibiting substance function during mammalian sexual development Cell 79 415-425

Belville C, Josso N and Picard J-Y (1999) Persistence of Müllerian derivatives in males American Journal of Medical Genetics 89 218-223

Burns RK (1939) Sex differentiation during the early pouch stages of the opossum (Didelphys virginiana) and a comparison of the anatomical 
changes induced by male and female sex hormones Journal of Morphology 65 497-547

Burns RK (1942) The origin and differentiation of the epithelium of the urogenital sinus in the oppssum, with study of the modifications induced by estrogens Carnegie Institute Contributions to Embryology 30 63-83

Burns RK (1955) Experimental reversal of sex in the gonads of the oppossum Didelphys virginiana. Proceedings National Academy of Sciences USA 41 669-676

Burns RK (1961) Role of hormones in the differentiation of sex. In Sex and Internal Secretions pp 76-158 Ed. WC Young. Williams and Wilkins, Baltimore

Couse JF, Hewitt SC, Bunch DO, Sar M, Walker VR, Davis BJ and Korach KS (1999) Postnatal sex reversal of the ovaries in mice lacking estrogen receptors alpha and beta Science $\mathbf{2 8 6} 2328-2331$

Couse JF, Curtis Hewitt S and Korach KS (2000) Receptor null mice reveal contrasting roles for estrogen receptor alpha and beta in reproductive tissues Journal of Steroid Biochemistry and Molecular Biology $\mathbf{7 4}$ 287-296

Coveney D, Shaw G and Renfree MB (2001) Estrogen-induced gonadal sex reversal in the tammar wallaby Biology of Reproduction 65 613-621

Eddy EM, Washburn TF, Bunch DB, Goulding EH, Gladen BC, Lubahn DB and Korachb KS (1996) Targeted disruption of the estrogen receptor gene in male mice causes alteration of spermatogenesis and infertility Endocrinology 137 4796-4805

Emmen JM, McLuskey A, Adham IM, Engel W, Verhoef-Post M, Themmen AP, Grootegoed JA and Brinkmann AO (2000) Involvement of insulinlike factor 3 (Insl3) in diethylstilbestrol-induced cryptorchidism Endocrinology 141 846-849

Fadem BH and Tesoriero JV (1986) Inhibition of testicular development and feminization of the male genitalia by neonatal estrogen treatment in a marsupial Biology of Reproduction 34 771-776

George FW and Wilson JD (1994) Sex determination and differentiation. In The Physiology of Reproduction pp 3-28 Eds E Knobil and JD Neill. Raven Press, New York

Gill WB, Schumacher GF, Bibbo M, Straus FH and Schoenberg HW (1979) Association of diethylstilbestrol exposure in utero with cryptorchidism, testicular hypoplasia and semen abnormalities Journal of Urology 122 36-39

Griffiths AL, Renfree MB, Shaw G, Watts LM and Hutson JM (1994) The tammar wallaby (Macropus eugenii) and the Sprague-Dawley rat: comparative anatomy and physiology of inguinoscrotal testicular descent Journal of Anatomy 183 441-450

Grocock CA, Charlton HM and Pike MC (1988) Role of the fetal pituitary in cryptorchidism induced by exogenous maternal oestrogen during pregnancy in mice Journal of Reproduction and Fertility 83 295-300

Gundersen HJ, Bagger P, Bendtsen TF et al. (1988) The new stereological tools: disector, fractionator, nucleator and point sampled intercepts and their use in pathological research and diagnosis Acta Pathologica Microbiologica et Immunologica Scandinavica 96 857-881

Hess RA, Buncik D and Bahr J (2001) Oestrogen, its receptors and function in the male reproductive tract - a review Molecular and Cellular Endocrinology 178 29-38

Hutson JM (1985) A biphasic model for the hormonal control of testicular descent Lancet 2 419-421

Hutson JM (1986) Testicular feminization: a model for testicular descent in mice and men Journal of Pediatric Surgery 21 195-198

Hutson JM, Ikawa H and Donahoe PK (1982) Estrogen inhibition of Müllerian inhibiting substance in the chick embryo Journal of Pediatric Surgery 17 953-959

Hutson JM, Donahoe PK and MacLaughlin DT (1985) Steroid modulation of Müllerian duct regression in the chick embryo Journal of Pediatric Surgery 17 953-959

Hutson JM, Shaw G, O WS, Short RV and Renfree MB (1988) Müllerian inhibiting substance production and testicular migration and descent in the pouch young of a marsupial Development 104 549-556

Hutson JM, Davidson PM, Reece LA, Baker ML and Zhou B (1994) Failure of gubernacular development in the persistent Müllerian duct syndrome allows herniation of the testis Pediatric Surgery International 9 544-546

Jefferson WN, Couse JF, Banks EP, Korach KS and Newbold RR (2000)
Expression of estrogen receptor beta is developmentally regulated in reproductive tissues of male and female mice Biology of Reproduction $62310-317$

Josso $\mathbf{N}$ and di Clemente $\mathbf{N}$ (1999) TGF- $\beta$ family members and gonada development Trends in Endocrinology and Metabolism 10 216-222

Korach KS (2000) Estrogen receptor knockout mice: molecular and endocrine phenotypes Journal of the Society of Gynecological Investigations 7 S16-17

Leihy MW, Shaw G, Wilson JD and Renfree MB (2001) Virilization of the urogenital sinus of the tammar wallaby is not unique to $5 \alpha$ androstane-3 $\alpha, 17 \beta$-diol Molecular and Cellular Endocrinology 181 $111-115$

Loeff DS, Imbeaud S, Reyes HM, Meller JL and Rosenthal IM (1994) Surgical and genetic aspects of persistent Müllerian duct syndrome Journal of Pediatric Surgery 29 61-65

Lucas JC, Renfree MB, Shaw G and Butler CM (1997) The influence of the anti-androgen flutamide on early sexual differentiation of the marsupial male Journal of Reproduction and Fertility 109 205-212

McLachlan JA, Newbold RR and Bullock B (1975) Reproductive tract lesions in male mice exposed prenatally to diethylstilbestrol Science 190 991-992

MacLaughlin DT, Hutson JM and Donahoe PK (1983) Specific estradiol binding in embryonic Müllerian ducts: a potential modulator of regression in the male and female chick Endocrinology 113 141-145

Naslund MJ and Coffey DS (1986) The differential effects of neonatal androgen, estrogen and progesterone on adult rat prostate growth Journal of Urology 136 1136-1140

National Health and Medical Research of Australia (1990) Australian Code of Practice for Care and Use of Animals for Scientific Purpose Australian Government Printer, Canberra

Nef S and Parada LF (1999) Cryptorchidism in mice mutant for Insl3 Nature Genetics 22 295-299

Nef S, Shipman T and Parada LF (2000) A molecular basis for estrogeninduced cryptorchidism Developmental Biology 224 354-361

Newbold RR, Suzuki Y and McLachlan JA (1984) Müllerian duct maintenance in heterotypic organ culture after in vivo exposure to diethylstilbestrol Endocrinology 115 1863-1868

Newbold RR, Bullock BC and McLachlan JA (1987) Müllerian remnants of male mice exposed prenatally to diethylstilbestrol Teratogenesis, Carcinogenesis and Mutagenesis 7 377-389

Nonneman DJ, Ganjam VK, Welshons WV and Vom Saal FS (1992) Intrauterine position effects on steroid metabolism and steroid receptors of reproductive organs in male mice Biology of Reproduction 47 723-729

O W-S, Short RV, Renfree MB and Shaw G (1988) Primary genetic control of somatic sexual differentiation in a mammal Nature 331 716-717

O'Donnell L, Robertson KM, Jones ME and Simpson ER (2001) Estrogen and spermatogenesis Endocrine Reviews 22 289-318

Pentikainen V, Erkkila K, Suomalainen L, Parvinen M and Dunkel L (2000) Estradiol acts as a germ cell survival factor in the human testis in vitro. Journal of Clinical Endocrinology and Metabolism 85 2057-2067

Prins GS (1992) Neonatal estrogen exposure induces lobe-specific alterations in adult rat prostate androgen receptor expression Endocrinology $1302401-2412$

Prins GS, Birch L, Habermann H, Chang WY, Tebeau C, Putz O and Bieberich C (2001) Influence of neonatal oestrogens on rat prostate development Reproduction, Fertility and Development 13 241-252

Rajfer J and Coffey DS (1978) Sex steroid imprinting of the immature prostate. Long-term effects Investigative Urology 16 186-190

Renfree MB and Blanden DR (2000) Progesterone and oestrogen receptors in the female genital tract throughout pregnancy in tammar wallabies Journal of Reproduction and Fertility 119 121-128

Renfree MB and Shaw G (2001) Germ cells, gonads and sex reversal in marsupials International Journal of Developmental Biology 45 557-567

Renfree MB, Fletcher TP, Blanden DR, Lewis PR, Shaw G, Gordon K, Short RV, Parer-Cook E and Parer D (1989) Physiological and behavioural events around the time of birth in macropodid marsupials. In Kangaroos, Wallabies and Rat Kangaroos pp 323-337 Eds G Grigg, P Jarman and I Hume. Surrey Beatty and Sons Pty Ltd, Sydney

Renfree MB, Wilson JD, Short RV, Shaw G and George FW (1992) Steroid 
hormone content of the gonads of the tammar wallaby during sexual differentiation Biology of Reproduction 47 644-647

Renfree MB, O WS, Short RV and Shaw G (1996) Sexual differentiation of the urogenital system of the fetal and neonatal tammar wallaby, Macropus eugenii. Anatomy and Embryology 194 111-134

Renfree MB, Coveney D and Shaw G (2001) The influence of oestrogen on the developing male marsupial Reproduction, Fertility and Development 13 231-240

Robertson KM, O'Donnell L, Jones ME, Meachem SJ, Boon WC, Fisher CR, Graves KH, McLachlan RI and Simpson ER (1999) Impairment of spermatogenesis in mice lacking a functional aromatase (cyp 19) gene Proceedings National Academy of Sciences USA 96 7986-7991

Ryhorchuk AR, Shaw G, Butler CM and Renfree MB (1997) Effects of a $5 \alpha$-reductase inhibitor, finasteride, on the developing prostate and testis of a marsupial Journal of Andrology 18 123-130

Shaw G, Renfree MB, Short RV and O WS (1988) Experimental manipulation of sexual differentiation in wallaby pouch young treated with exogenous steroids Development 104 689-701

Shaw G, Renfree MB, Leihy MW, Shackleton CH, Roitman E and Wilson JD (2000) Prostate formation in a marsupial is mediated by the testicular androgen $5 \alpha$-androstane- $3 \alpha, 17 \beta$-diol Proceedings National Academy of Sciences USA $9712256-12259$

Shono T, Ramm-Anderson S, Goh DW and Hutson JM (1994) The effect of flutamide on testicular descent in rats examined by scanning electron microscopy Journal of Pediatric Surgery 29 839-844

Singh J and Handelsman DJ (1999) Morphometric studies of neonatal estrogen imprinting in the mature mouse prostate Journal of Endocrinology 162 39-48

Tyndale-Biscoe CH and Hinds LA (1989) Influence of the immature testis on sexual differentiation in the tammar wallaby, Macropus eugenii
(Macropodidae: Marsupialia) Reproduction, Fertility and Development $1243-254$

Visser JA, McLuskey A, Verhoef-Post M, Kramer P, Grootegoed JA and Themmen AP (1998) Effect of prenatal exposure to diethylstilbestrol on Müllerian duct development in fetal male mice Endocrinology 139 4244-4251

vom Saal FS, Timms BG, Montano MM et al. (1997) Prostate enlargement in mice due to fetal exposure to low doses of estradiol or diethylstilbestrol and opposite effects at high doses Proceedings National Academy of Sciences USA 94 2056-2061

Weibel ER (1979) Stereological Methods Academic press, London

Whitworth DJ, Shaw G and Renfree MB (1997) Müllerian duct regression in a marsupial, the tammar wallaby Anatomy and Embryology 196 $39-46$

Wilson JD, George FW, Shaw G and Renfree MB (1999) Virilisation of the male pouch young of the tammar wallaby does not appear to be mediated by plasma androgens Biology of Reproduction 61 471-475

Yasuda Y, Kihara T and Tanimura T (1985) Effect of ethinyl estradiol on the differentiation of mouse fetal testis Teratology 32 113-118

Zimmermann S, Steding G, Emmen JM, Brinkmann AO, Nayernia K, Holstein AF, Engel W and Adham IM (1999) Targeted disruption of the Insl3 gene causes bilateral cryptorchidism Molecular Endocrinology 13 $681-691$

Received 20 December 2001.

First decision 19 February 2002.

Revised manuscript received 18 March 2002.

Accepted 5 April 2002. 